
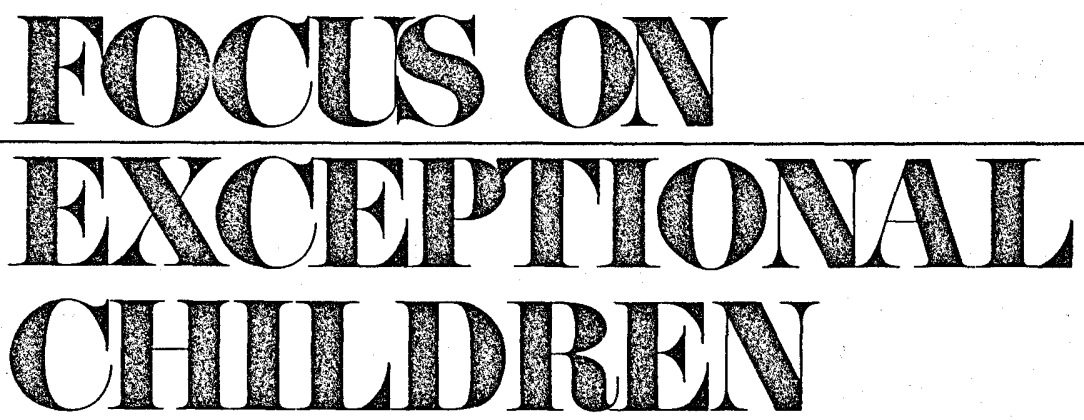

\title{
NINE STEPS TO THE DIAGNOSTIC PRESCRIPTIVE PROCESS IN THE CLASSROOM
}

\section{TEACHER-DEVELOPED INSTRUCTIONAL PRESCRIPTIONS}

\section{Mary Ross Moran ${ }^{1}$}

Sophisticated sytems of evaluative-diagnostic-remedial services in the schools have accompanied the movement toward individualizing instruction. Teachers can refer a child to the school psychologist, the reading specialist, the methods and materials consultant, or other ancillary personnel to obtain diagnostic information and recommendations for remediation. The resulting emphasis upon testing by experts has led to an assumption that intervention by the teacher must await evaluation by a diagnostic specialist. Since delays of several months are common, the referral system results in loss of valuable time. The more critical loss, however, is the lack of involvement of the classroom teacher in the diagnostic process.

Since the ultimate responsibility for instructional decisions rests with the classroom teacher who must carry out any special program regardless of who designs it, there are many reasons to utilize the unique skills of the teacher at all stages of the evaluative-diagnostic-remedial continuum. This can be accomplished through teacher development of instructional prescriptions, with evaluation and remediation centered in the child's own classroom.

There are usually two reasons offered by teachers who hesitate to undertake the role of a diagnostic-prescriptive specialist in the classroom. First, they believe they must be trained to administer and interpret standardized tests in order to evaluate a child intensively. Second, they feel they cannot design a program for a child unless they know his level of intellectual functioning.

It is helpful to remind teachers that standardized tests developed as short cuts, as controlled samples of behavior upon which the clinician relies because he can spend little time with a single child. The clinician who gives a well-selected battery of standardized instruments which are carefully interpreted can indeed learn a great deal about a child in two hours. But the classroom teacher who has access to unlimited samples of behavior over time can be taught to interpret these data just as carefully to yield information which is more directly applicable to instruction. In general, standardized norm-referenced tests designed to provide variability and to distinguish between children have limited usefulness in planning an individual instructional program for a specific child.

1. Mary Ross Moran is a Teaching Associate, Department of Special Education, University of Kansas, Kansas City, Kansas.

- Love Publishing Company 1975. 
Perhaps the only relevance of the IQ for prescription development is the possibility that a child whose intellectual functioning is below average will require more trials to reach criterion. As this will become obvious through informal testing and initial teaching, there is no reason to await an IQ before planning a program. If IQ were indeed necessary to plan instruction, there is evidence that teachers are good estimators of IQ. Studies which have involved the use of deliberately inflated IQ have revealed that teachers can distinguish inflated scores from true scores (Fleming \& Anttonen, 1971).

The requirements for a teacher who would undertake the diagnostic-prescriptive process in the classroom do not then include the skills of a clinician. Instead, they encompass abilities already present in a good teacher's instructional practices. Prescription development does require that certain points of view be cultivated.

First, the teacher must become skills-oriented. This means that she must look at a child primarily in terms of specific academic strengths and weaknesses, rather than concerning herself with etiology or diagnostic labels. For purposes of preparing prescriptions, the relevant information is precise isolation of specific task behaviors as exhibited by an individual child.

Second, the teacher must become a systematic observer of behavior. She must learn to examine task performance closely. Observation tells a teacher whether the child is impulsive or deliberative, a planner or a trial-and-error

FOCUS ON EXCEPTIONAL CHILDREN is published monthly except June, July, and August as a service to those concerned with mentally retarded and emotionally disturbed children. This journal is abstracted and indexed in Exceptional Child Education Abstracts. Subscription rates, $\$ 9.50$ per year. Copyright 1975, Love Publishing Company. All rights reserved. Reproduction in whole or part without written permission is prohibited. Printed in the United States of America. Second class postage is paid at Denver, Colorado.

$$
\begin{gathered}
\text { Executive and Editorial Office } \\
6635 \text { East Villanova Place } \\
\text { Denver, Colorado } 80222 \\
\text { Telephone (303) 757-2579 }
\end{gathered}
$$

\section{EDITORIAL BOARD}

Edward L. Meyen

University of Kansas
Glenn A. Vergason

Georgia State University

Richard J. Whelan

University of Kansas Medical Center
Sallie Carmachel Keeney Managing Editor
Stanley F. Love Publisher learner, highly verbal or action-oriented, dependent upon aid or able to work alone, a risk-taker or afraid to chance failure. Such characteristics have implications for instructional decisions, and the teacher must be alert to the child's problem-solving style as well as his absolute skill performance.

Third, the teacher must be flexible enough to engage in trial teaching. This term is similar in meaning to clinical teaching (Lerner, 1971) or remedialdiagnosis (Beery, 1968); it is here used to describe systematic modification of methods and materials in response to the child's reactions to them in the actual instructional situation. The diagnostic-prescriptive process is dynamic, not static. The prescription is not engraved in stone; instead, it is a working guide which is revised to correspond to new information yielded by the instructional interaction over time.

Following are nine major steps to be undertaken toward a systematic approach to the diagnostic-prescriptive process in the classroom.

\section{EVALUATE PRIOR DATA}

An investigation of available background information in school records can be useful in developing hypotheses prior to informal testing.

\section{Cumulative Records of Grades and Test Results}

The cumulative record can answer the following questions: Which academic skills areas are relatively low as indicated by letter grades? What was the time of onset of lower grades? What is the absence record? Have test results corresponded to classroom performance?

In preparing an informal assessment, it is important to focus on critical skills while avoiding unnecessary testing. The relative achievement described by letter grades aids in planning the emphasis of informal testing by revealing which skills areas are comparatively intact and which are in need of remedial attention.

The second contribution of the cumulative record is to establish the time of onset of academic problems. Patterns of development appear. For example, if the record shows that low grades began in first grade and continued, the problem is likely to involve deficits in the correlates of learning such as motor, perceptual, or language abilities so that basic readiness skills may not be established. If, instead, the child earned average marks in the first few 
grades but began to break down in third or fourth grade, he is probably intact in terms of prerequisite subskills but may demonstrate an uneven profile of skills deficits at higher levels. This information is helpful in determining whether one is dealing with developmental disabilities or secondary problems manifested in low achievement.

The absence record should be compared to the time of onset of problems. If a child missed thirty days of school in first grade, inadequate continuity of instruction is as suspect as is developmental lag to explain lack of readiness skills. The absence record is reviewed for length of absences, the time of year when they occurred, and the grades which followed. Frequent absence over years suggests serious health or family problems, while absence only during the winter quarter may indicate chronic upper respiratory infections and possible conductive hearing loss. The record may show that a child has missed enough instruction to account for failure to master specific skills.

Standardized test results should be investigated beyond a global percentile or grade-equivalent score. For children who are not achieving, the total score is the least important piece of information to a teacher who should instead be alert to these questions: Did the child respond in a way which indicates that he misunderstood test directions? Did he miss relatively easy items while answering more difficult ones correctly? Did he respond randomly or were errors systematic? Did he complete as many items as classmates, or did he overdeliberate or refuse to attempt items?

Answers to these questions require access to the test booklet completed by the child. If available, this is the best source of information. However, the computer printout provided by a scoring service does show relative performance, and a blank test booklet can reveal the demands which were placed on the child.

The most important point for a teacher to keep in mind when evaluating standardized test results including IQ is that a child cannot do better than the level of which he is capable but he can do a great deal worse if he is anxious or unsure of directions. It is useful to consider such test scores as a minimum point on the child's range, with his true score occurring somewhere above that level. Another factor to remember is that the test-retest reliability of a subtest is lower than that of the global test. For this reason, a profile should be viewed as an indicator of relative strengths and weaknesses while little weight is given to the absolute score of any single subtest. Furthermore, the standardized conditions prohibit modifications such as extending time, altering stimulus or response mode, limiting choices or other changes which might make it possible for a child to perform. Thus standardized tests offer no clues to compensatory behaviors of which a given child might be capable.

\section{Anecdotal Teachers' Reports}

Such records offer insight into behavior patterns and social interactions. For example, comments to the effect that the child does not follow directions, does not complete work, engages in repetitive motor activity, or gets lost in the building may be clues to the disorganized behavior associated with developmental disabilities. Comments about social withdrawal, aggressive acts, complaints of frequent illness or extreme reactions to ordinary events suggest unusual emotional stress. Such information is helpful in planning motivational strategies and in determining how much structure a child needs. If a teacher believes that such comments may prejudice her view of a child, it is a good idea to meet a new child informally to gain original impressions before consulting the records.

\section{Health Record}

The school nurse may have been alerted to a physical problem which affects learning, or she may know that medication is administered before a child comes to school. A sweep check may have indicated that a full hearing evaluation should be conducted, but there may have been no follow up on the referral. Or the record may show that the child once wore glasses although the teacher notes that he is not now wearing them. Indications that visual or auditory acuity should be evaluated are frequently uncovered by checking the health record.

\section{CONDUCT INFORMAL CLASSROOM ASSESSMENT OF SKILLS}

Informal testing can be structured to fit into a regular daily routine or scheduled during planning time or after school. Many teachers prefer at least one individual session to enable them to focus on a single child without distraction. This permits close observation and responsive modification of test activities. After basic skills are tested on a one-to-one basis, tasks which require further investigation can be given while other children are in the room. 
By observing the child under both situations, the teacher can assess the child's ability under optimal conditions and in the setting which approximates the day-to-day conditions under which he is expected to work.

For prescriptive planning, the testing of choice is criterion-referenced rather than norm-referenced, diagnostic rather than survey, and administered in a flexible, responsive atmosphere rather than under standardized conditions. The purpose of informal testing is to sample behaviors which are as close as possible to the criterion or outcome behaviors. This is accomplished by using for testing the same materials which the child will use in class. Maximum information is extracted from such informal testing by systematically altering task demands so that the child's ability to use compensatory mechanisms or to use specific input-output mode combinations can be investigated.

The ideal test battery consists of an informal reading inventory drawn from the basal series adopted by that school, supplemented by a skills test drawn from the series' scope and sequence chart; a spelling test based on sight words read by the child in the informal inventory; a writing sample encompassing words and sentences read by the child; a sample of oral language based on retelling of a story; and an arithmetic sample drawn from the scope and sequence chart for the classroom series.

\section{Reading Assessment}

Following the general practice of testing down, so that terminal behaviors are sampled to learn which subskills must be tested, it is best to begin with an informal reading inventory which requires recognition of both flashed and untimed words in isolation, followed by paragraph reading, a comprehension check, a listening capacity test, and finally a skills inventory selected from the results of the word and paragraph reading. There are several good sources of information on developing an informal reading test from the basal reader (Otto \& McMenemy, 1966; Kress \& Johnson, 1965; Betts, 1957).

Both silent and oral paragraph reading should be followed by at least four comprehension questions prepared in advance. One question should request a definition of a word in the passage, a second should require recall of a fact, a third should ask the child to draw an inference from the facts presented, and the fourth should request the main idea of the passage. To test sequencing ability as well as recall, ask the child to retell one or two passages in the order in which events occurred.

After the paragraph reading is completed, compute the error percentage for each oral passage to determine the child's independent reading level (99\% word recognition; $100 \%$ comprehension), and instructional reading level (95\% word recognition, $75 \%$ comprehension). Beginning at the point just above the instructional level, read the higher level passages to the child and follow with comprehension questions. This will establish the child's listening capacity level (75\% comprehension).

Though it involves a considerable amount of preparation, the informal reading inventory drawn from the basal series can be reused to test every child in the class, with each child in a different range along the continuum of graded selections. The inventory yields answers to a number of questions.

First, what is the child's potential instructional level? This is determined on the basis of the discrepancy between the child's expectancy level, as computed by a standard formula (Lerner, 1971), or the child's listening capacity level and his present instructional reading level. For purposes of prescriptive planning, the listening capacity level of the informal reading inventory is considered a good estimate of a child's potential instructional level because he has the vocabulary and linguistic competence to understand material at that level although he cannot comprehend it visually due to word recognition problems. If a child comprehended material read to him with $75 \%$ accuracy at a 5.2 level but his instructional level is 3.1 , the 5.2 reader is a realistic goal to work toward in planning remedial instruction.

Second, what is the relationship between the flashed word recognition score and the untimed word recognition score? This yields information on the child's ability to utilize word attack skills. If there is no difference between his flashed and untimed scores, he lacks word analysis cues since he cannot improve his score by taking time to decode an unknown word. If there is a difference between the two scores, an item-by-item analysis can detail the subskills to be tested more intensively.

Third, what is the pattern of oral reading errors? This is determined by computing a simple frequency percentage of the different types of errors. For example, a given child may exhibit $50 \%$ substitutions, $25 \%$ mispronunciations, and $25 \%$ insertions. This is quite a different picture from the child whose error profile shows $50 \%$ omissions, $25 \%$ examiner pronunciations, and $25 \%$ substitutions. The first 
child is willing to experiment; he is probably a context reader who guesses on the basis of meaning and his comprehension may be quite good although he lacks word attack skills. The second child will not attempt to analyze a word if he does not recognize it on sight, and he has not learned to predict a probable word on the basis of the sense of the passage; however, his precision will be an advantage in learning word attack skills. Thus error patterns can reveal the child's reading "personality." A more intensive analysis of errors, such as the types of substitutions, offers greater precision. Does the child substitute on the basis of configuration cues, initial consonant, the meaning of the passage, or following any other system? Are the words he substitutes real words or nonsense approximations to English words? Does the substituted word fit or violate the sense of the passage? Answers to these questions are useful in selecting subskills to be further investigated.

Fourth, what is the relationship among types of comprehension questions answered and missed? A child who correctly answered $100 \%$ of the factual questions but missed all of the inference questions and $50 \%$ of the vocabulary questions is quite different from the child who answered only $50 \%$ of the factual questions but $100 \%$ of the vocabulary and main idea questions. The first child is a literal reader whose recall is good but who cannot build on or bring problem-solving techniques to bear on the facts he knows. The second child is not sufficiently attentive to detail, but he can develop the meaning of words from context and he can grasp the important ideas of a passage. This type of analysis can be used to develop study guides or other aids to comprehension for specific children.

Fifth, what is the relationship between oral reading rate and silent reading rate? In a mature reader, silent reading rate should be a great deal faster than oral rate. Even in a developing reader, this relationship should show up. If silent rate is not faster, there are several possibilities. Perhaps the child is overanalyzing words rather than processing them as units. Sometimes an overemphasis upon phonics instruction results in a reader who uses word attack skills for familiar words which he should know at sight. Slow silent rate can also be an indication of a word-by-word reader, who plods along rather than making predictions and monitoring his reading against the sense of the passage.

Sixth, what is the relationship between oral reading comprehension and silent reading comprehension? Children who are slow silent readers are likely to exhibit low comprehension scores as well. They may regress and reread the same line a number of times in an attempt to understand or remember it, or they may be subject to intrusive thoughts when the auditory reinforcement of oral reading is not available to them. The child who demonstrates poor silent comprehension is not a likely candidate for lengthy independent seatwork; he should be kept actively involved in tasks by multisensory approaches in order to anchor his attention to the stimulus materials. All these pieces of information gained from the informal inventory have implications for planning an instructional program.

The next part of the reading evaluation is the subskills test based upon the scope and sequence chart. This is a diagnostic test which draws on specific skills listed on a scope and sequence chart to isolate the child's deficits. The instrument is drawn up to specify first the skill, second the task which will sample the skill, third the identification of stimulus and response modes, fourth the correlative abilities or subskills which are presumed to underlie the skill. A sample test drawn from primary levels of the scope and sequence chart might include the items presented in Figure 1.

In addition to presenting the items as given in the task section, the input and output modes should be altered if the child cannot perform. For example, a verbal response as required by the blending task may not be possible, but the child may be able to point to the correct word if it is presented to him in print as a multiple choice task. Tasks should be presented in a variety of ways so that different combinations of visual, auditory, and motor responses are required.

\section{Spelling}

A single exception to using classroom texts is made in testing spelling. A teacher-constructed spelling test based on the results of the informal reading inventory is preferred over the classroom spelling text because the text is likely to contain stimulus words which are not in the child's reading vocabulary. Since the child has just read a list of words from a graded basal reader, this list identifies words which are in the child's reading vocabulary. Selecting words which have been read by the child is an effective way to ensure that spelling skills are being isolated from word recognition skills.

Ten to twenty words should be selected from the child's reading vocabulary, at the highest level of word recognition 
Figure 1

\section{SKILL}

TASK
Given orally a series of up to three individually pronounced sounds which form a word in the child's oral vocabulary, the student will blend these sounds into a word.

2. Identifying like and unlike words in print.

3. Recognition of long vowel sounds in words.

\section{Associating consonant} sounds with corresponding grapheme in initial position.

\section{Given a list of Dolch sight words in primary type in \\ Visual-Visual
Motor} random order, the student will match pairs of duplicated words by pointing to the matching word when the teacher points to a stimulus word.

Given orally a series of words containing long vowel sounds, the student will identify by circling with a pencil the corresponding letter presented in random order in primary type.

Given a set of words orally, the student will point to the initial consonant of each word when presented in random order in primary type.
Auditory-Verbal

Auditory Discrimination Auditory Sequential Memory Vocal Encoding
Auditory-Visual Motor

\section{Auditory-Visual Motor}

\author{
Visual Discrimination \\ Form Constancy \\ Gross Motor Coordination
}

\begin{abstract}
Auditory Discrimination Visual Discrimination Auditory-Visual Association Fine Motor Coordination
\end{abstract}

skill. Individual stimulus words should be selected in such a way that a variety of initial and final consonants, consonant clusters, blends and vowel patterns are represented. A balance should be sought between words which are phonetic for spelling and words which are not phonetic.

In addition to isolating spelling problems as distinguished from word recognition problems, it is important to separate spelling from recall or memory factors and from impairments of motor execution. In order to accomplish this isolation, the same spelling words are presented in three ways. First, the child is asked to write the words spontaneously to oral dictation. Then, the words which were not spelled correctly in that way are dictated to the child a second time and he is asked to spell them orally. Finally, words which have not been correctly spelled in either way are presented a third time printed on paper as a multiple choice task which requires the child to select one of three alternate spellings.

The oral spelling test has proved to be effective in identifying children who have visual memory or motor execution problems which interfere with written spelling, but who can recall the auditory sequence of a word. The 
multiple choice task is useful for the child who has motor problems, but it usually identifies the child who has memory or recall problems, such as the child with auditory memory or sequencing deficits who nevertheless recognizes a correct visual representation of the word. Figure 2 outlines how the task is set up.

By presenting the same materials in three ways, the teacher gains a good sample of the child's spelling strengths and weaknesses in a very brief testing. Error analysis can answer questions such as these: Do letter substitutions appear to be related to auditory similarity, such as $/ t /$ for $/ \mathrm{k} /$, or to visual similarity, such as $/ \mathrm{b} /$ for $/ \mathrm{h} /$ ? Are vowel substitutions phonetic? Are there indications of overreliance on auditory cues such as "shur" for "sure" or "lisen" for "listen"? Are correct letters placed in transposed order as in "fram" for "farm"? Are these reflections of faulty pronunciation as in "liberry" or "pichur"? Does the child demonstrate any knowledge of rules such as changing $/ \mathrm{y} /$ to $/ \mathrm{i} /$ before suffixes or doubling consonants?
It is informative to study the spelling performance in conjunction with the word recognition performance, since errors often reflect phonics problems common to both.

\section{Writing}

Because it provides a means of isolating problem areas, the writing test includes three types of tasks (see Figure 3). First, the child is asked to write letters, words, or sentences spontaneously to dictation. Then he is asked to copy letters, words, or sentences from one paper on his desk to another. Finally he is to copy letters, words, or sentences from a vertical to a horizontal surface, as from the blackboard to a paper on his desk.

The purpose of presenting both spontaneous writing and copying tasks is to separate the language formulation or recall problem from the motor execution problem.

Figure 2

\begin{tabular}{|c|c|c|c|}
\hline SKILL & TASK & S-R MODES & CORRELATES \\
\hline $\begin{array}{l}\text { 1. Writing spelling words } \\
\text { to dictation. }\end{array}$ & $\begin{array}{l}\text { Given a series of dictated words } \\
\text { which are in the child's sight } \\
\text { vocabulary, the student will } \\
\text { write them in cursive script in } \\
\text { a vertical list. }\end{array}$ & $\begin{array}{l}\text { Auditory-Visual } \\
\text { Motor }\end{array}$ & $\begin{array}{l}\text { Auditory Discrimination } \\
\text { Auditory Memory } \\
\text { Auditory-Visual Association } \\
\text { Visual Memory } \\
\text { Visual Sequential Memory } \\
\text { Fine Motor Coordination }\end{array}$ \\
\hline $\begin{array}{l}\text { 2. Orally spelling words } \\
\text { to dictation. }\end{array}$ & $\begin{array}{l}\text { Given a series of dictated words } \\
\text { which are in the child's sight } \\
\text { vocabulary, the student will } \\
\text { verbally state in order the } \\
\text { letters which appear in the } \\
\text { words. }\end{array}$ & Auditory-Verbal & $\begin{array}{l}\text { Auditory Discrimination } \\
\text { Auditory Memory } \\
\text { Auditory Sequential Memory }\end{array}$ \\
\hline $\begin{array}{l}\text { 3. Identifying a correctly } \\
\text { spelled word in print. }\end{array}$ & $\begin{array}{l}\text { As the teacher pronounces a } \\
\text { word, the student will point to } \\
\text { the one of four words printed } \\
\text { in primary type which is a } \\
\text { correct spelling of the stimulus } \\
\text { word. }\end{array}$ & $\begin{array}{l}\text { Auditory-Visual } \\
\text { Motor }\end{array}$ & $\begin{array}{l}\text { Auditory Memory } \\
\text { Visual Memory } \\
\text { Auditory-Visual } \\
\quad \text { Association } \\
\text { Visual Discrimination } \\
\text { Gross Motor Coordination }\end{array}$ \\
\hline
\end{tabular}


Figure 3

\begin{tabular}{llll}
\hline SKILL & TASK & S-R MODES & CORRELATES \\
\hline
\end{tabular}

1. Writing letters of the alphabet in manuscript to dictation.

2. Writing letters of the alphabet in manuscript in alphabetical order.

3. Copying letters of the alphabet in cursive script on a plane surface.

4. Copying letters of the alphabet in cursive script from a vertical to a horizontal surface.
Given orally a set of isolated

letter names, singly and in

random order, the student

will print the letters in

dictated order on a lined

primary tablet.

Given an incomplete sequence

of letters in pica type in upper-

case form, the student will insert

in manuscript the letter which

belongs in each blank space.

Given a set of letters written in cursive on a sheet of paper placed on his desk, the student will write the letters in correct sequence on a lined primary tablet.

Given a set of letters written in cursive on a blackboard, the student will write the letters in correct sequence on a lined primary tablet.
AuditoryVisual Motor

Auditory Discrimination

Auditory-Visual Association

Visual Memory

Directional Orientation

Fine Motor Coordination

\section{Visual-Visual}

Motor

Visual Discrimination
Visual Sequential Memory
Directional Orientation
Visual Closure

Visual-Visual Motor

\section{Visual Discrimination \\ Directional Orientation \\ Fine Motor Coordination}

\author{
Visual Discrimination \\ Form Constancy \\ Directional Orientation \\ Fine Motor Coordination
}

Many children who cannot write spontaneously demonstrate visual memory or revisualization problems. A copying task which requires the same motor activities follows the spontaneous writing, and if the child can then perform, motor impairment is ruled out. The copying task is then duplicated from another plane to determine whether that affects performance, since children with perceptual problems sometimes cannot shift from one plane to another without distorting form. By systematically altering the task, the teacher attempts to isolate areas of deficit.

To test language formulation with children who are able to write sentences, it is best to ask the child to write something undemanding in terms of memory or vocabulary requirements. If the child has just completed the information reading inventory, he might be asked to write an event he remembers from one story. Or, he can be asked to write a sentence or two about what he did the day before. This type of written sentence construction permits evaluation of word order, use of plural and tense markers, and general usage.

\section{Oral Language Formulation}

The child's linguistic abilities are usually apparent in casual conversation, but it sometimes helps to determine whether he can construct sentences by taking an informal language sample. The easiest way to do this is to present picture stimuli which illustrate stories and ask the child to tell the story. Avoid questions which constrain partial responses, such as asking what, who, when, or where. Instead, if the child hesitates, say, "Tell me more about 
it," or "Finish the story for me." If possible, tape-record the storytelling so that the language sample can be reviewed to answer questions such as: Are words in conventional order or is syntax confused? Are function words such as prepositions, articles, conjunctions represented in the sample? Are personal pronouns correct as to gender and case? Are plural nouns and past tense forms of verbs used? Are auxiliary verbs used? Are compound and complex sentences represented? Such a language sample on tape allows for concentration on language formulation problems or articulation defects which should be brought to the attention of the speech and language clinician. With her guidance, such structures can be included in the classroom prescription.

\section{Arithmetic Computation and Reasoning}

Again, the scope and sequence chart of the classroom text is the basis of the testing. The test specifies stimulus and response modes which are varied to provide isolation of deficits. By making the task more concrete or by eliminating the memory or recall factor, the teacher can help the child to demonstrate what he needs in order to perform arithmetic computations (see Figure 4).

When written computation on a worksheet is presented, it becomes important to distinguish spatial and directionality problems from erroneous concepts about the operation. For example, a common error in subtraction with borrowing is illustrated by: $\frac{-17}{4}$ and a multiplication

Figure 4

\begin{tabular}{|c|c|c|c|}
\hline SKILL & TASK & S-R MODES & CORRELATES \\
\hline $\begin{array}{l}\text { 1. Writing numerals up to } \\
10 .\end{array}$ & $\begin{array}{l}\text { Given orally a whole number up } \\
\text { to } 10, \text { the student will write the } \\
\text { corresponding numeral on lined } \\
\text { primary paper. }\end{array}$ & $\begin{array}{l}\text { Auditory-Visual } \\
\text { Motor }\end{array}$ & $\begin{array}{l}\text { Auditory Memory } \\
\text { Visual Memory } \\
\text { Auditory-Visual Association } \\
\text { Fine Motor Coordination }\end{array}$ \\
\hline $\begin{array}{l}\text { 2. Identifying written } \\
\text { numerals. }\end{array}$ & $\begin{array}{l}\text { Given a printed list of numerals } \\
\text { up to } 10 \text { arranged in random } \\
\text { order in a horizontal sequence, } \\
\text { the student will name each } \\
\text { numeral in the order it appears. }\end{array}$ & Visual-Verbal & $\begin{array}{l}\text { Visual Discrimination } \\
\text { Directional Orientation } \\
\text { Auditory Memory } \\
\text { Vocal Encoding }\end{array}$ \\
\hline $\begin{array}{l}\text { 3. Matching sets up to } \\
10 \text {. }\end{array}$ & $\begin{array}{l}\text { Given a picture of up to six } \\
\text { sets composed of up to ten } \\
\text { objects, the student will iden- } \\
\text { tify equal pairs of sets by } \\
\text { drawing a pencil line between } \\
\text { them. }\end{array}$ & $\begin{array}{l}\text { Visual-Visual } \\
\text { Motor }\end{array}$ & $\begin{array}{l}\text { Visual Discrimination } \\
\text { Fine Motor Coordination }\end{array}$ \\
\hline $\begin{array}{l}\text { 4. Counting concrete } \\
\text { objects up to } 10 .\end{array}$ & $\begin{array}{l}\text { Given a set of manipulative } \\
\text { objects up to } 10 \text {, the student } \\
\text { will identify each object by } \\
\text { naming in sequence the } \\
\text { corresponding ordinal } \\
\text { number. }\end{array}$ & Visual-Verbal & $\begin{array}{l}\text { Visual Perception } \\
\text { Auditory Memory } \\
\text { Auditory Sequential Memory } \\
\text { Vocal Encoding }\end{array}$ \\
\hline
\end{tabular}


error by: $\frac{143}{123}$ Although these errors are likely to represent erroneous concepts about the operation, the spatial element should be ruled out by indicating the correct direction of the operation and asking the child to repeat the computation. It is also sometimes the case that the child understands the direction of the operation, but he transposes the numbers when writing his answer. Directional errors or spatial orientation problems should always be considered if answers fit such a pattern.

When word problems are introduced, it is necessary to isolate skills specific to problem-solving activities as distinct from reading problems. The child should be given a written problem and asked to read it and solve it. If he cannot do so, he should be asked to read the problem aloud. If he does not read with $95 \%$ word recognition, the problem should be read to him. The following questions should be asked: What numbers are to be used in the computation? What is the computational operation? What is an estimate of the answer? Although problem-solving ability is more difficult to assess than is computation, the child's capacity to reason to a correct procedure should be sampled in the informal testing.

The informal assessment procedures suggested above represent a considerable investment of teacher time in preparation, administration, and interpretation. Of course, the informal reading inventory and the skills tests from the scope and sequence charts can be used for any number of children once they are developed. The time and effort are justified. Only by sampling performance on the materials actually used in her class can the teacher ensure that the assessment will yield information that is specific, skills based, and relevant to the everyday tasks of the classroom.

\section{SET PRIORITIES FOR REMEDIATION}

When assessment has been carried out, the next task is to determine which skills are to be included in the prescription and in what order of presentation. Because it is not possible to work simultaneously on all deficits for all children, a limit must be placed on the skills to be covered by the prescription. Many teachers decide arbitrarily that they will work with the five or six most critical needs of each child initially, then add another deficit area from the bottom of the list as the higher priority items reach criterion. Such a plan calls for a systematic method of setting priorities. There are at least three considerations.

\section{Subskills Prerequisite to Higher Skills}

The major advantage of using the scope and sequence chart for skills testing is that the skills are presequenced and the teacher can see at a glance which must precede and which can come later. Thus skills which require prescriptive planning can be arranged in the order in which they appear on the scope and sequence chart, in order to ensure that prerequisite subskills will be developed before higher skills are attempted. Of course, any subskills which could be considered in the readiness range, such as letter recognition and basic concepts of size and number, are obvious prerequisites. For higher level skills, however, the scope and sequence charts of classroom series provide the best guide to priorities.

\section{Balance of Strong and Weak Modalities}

A second way in which priorities are determined is in accord with the child's need for specific stimulus restrictions. Although pure auditory or visual learners are rare, it is important to consider a child's modality preference if he has one. For example, if a child seems to be primarily a visual learner, this type of activity should take first priority over auditory tasks so that the child can gain a success experience early in his program. As he demonstrates success with highly visual materials, the priority should shift toward auditory tasks so that neglect will not further weaken that modality.

\section{Student and Teacher Goals}

Another way to set priorities is to base them on the best fit between the teacher's goals and the child's own goals. This should be handled by a frank interview at the conclusion of the informal assessment in which the child is told what his needs are and how the teacher plans to remediate skills deficits. This interpretation conference is an ideal format to elicit the child's own goals and to discuss their relationship to those of the teacher so that the two members of the team are not working at cross purposes. A good way to compromise between teacher and pupil goals is to use the child's preferred tasks as reinforcers following each performance of the teacher's priority tasks. So long as the child's wishes are being incorporated into the prescription, he will tend to view the work as a joint undertaking toward mutual goals. 


\section{STATE BEHAVIORAL OBJECTIVES}

Clearly stated behavioral objectives allow both student and teacher to determine with precision when goals have been met. There are a number of sources of information on the preparation of instructional objectives (Mager, 1962; Kibler, et al., 1970). There are three essential elements in a behavioral objective.

\section{Behavior Which Is Observable and Measurable}

The statement must specify clearly what the student is to do to demonstrate that he has mastered the task. The child's response must be one which can be directly observed and measured. It may be useful to place overt behaviors into three classes based upon the type of activity the learner is to perform.

The discrimination objective requires the student to select from two or more alternatives by responding to differences or to likenesses. The overt activity would be matching, sorting, or choosing. The verbal objective involves providing oral spontaneous language or an imitative response. Overt activity includes naming, listing, defining, describing, repeating, spelling. The motor performance objective requires physical action, or manipulating instructional materials through gross or fine motor activity. Examples of overt behaviors are pointing, marking, drawing, copying, replacing, writing. Of course the three types of objectives can be combined in a single task, but it aids in sorting stimulus and response modes if they are considered separately.

\section{Conditions under Which Behavior Is to Occur}

The objective must specify what the child will be given in order to make the response. List or exclude any concrete manipulative materials or any learning aids which the student may or may not use in his terminal performance. Specify any particular method which he is to follow. Identify any materials or information which will be provided, including the size, type of script, numbers of items on a page, or any other relevant stimulus information.

\section{Criteria for Judgment of Acceptability}

Define criteria for performance which will detail how rapidly, accurately, frequently he must perform or the number, percentage, or proportion of correct responses which will be acceptable. If a time limit is to be imposed, specify the period exactly. Figure 5 contains examples of instructional objectives that may be helpful.

\section{SELECT METHODS AND MATERIALS}

Although an achieving child is able to work toward general objectives which cover broad content and skills areas over a long instructional period, a child with skills deficits requires more readily attainable goals presented in brief sequential units for incremental learning. Because the goal with an achiever is to maintain the task behaviors he is already using, he can be placed on a relatively lean or

Figure 5

\section{DISCRIMINATION OBJECTIVE}

Given a list of typewritten lower case letters including no other reversible forms, the student will correctly match by pointing to the typewritten letters $b$ and $d$ within ten seconds of presentation.
Given a picture depicting an action by a boy or a girl, the student will insert into an incomplete caption read by the teacher the correct personal pronoun "he" or "she" within two seconds after the caption is read.
MOTOR OBJECTIVE

Given a 9 by 12 inch wooden puzzle with one irregularly shaped part removed, the student will replace the puzzle part in its proper position within ten seconds of presentation. 
infrequent reinforcement schedule. A child with deficits, however, needs continuous reinforcement in order to establish new behaviors. This means that objectives should be set up so that he can reach them within a reasonable time and on a regular schedule.

\section{Adjustment of Instructional Approaches}

Success with a learning task may not be sufficient reinforcement for a child who has come to devalue school experiences. External consequences such as free time for games, classroom privileges, or even edibles may be necessary to maintain motivation. If so, such consequences should be written into the prescription.

Because of uneven skills development or a stronger visual or auditory style, other modifications may be suggested. For example, the child who cannot perform arithmetic operations with the class following oral directions may be able to do so if the teacher provides a visual demonstration; or a child who cannot work independently because he cannot read directions can do quiet seatwork if directions are put on tape and given to him through earphones. Most remedial learners will require considerable use of audio-visual aids. Some may be candidates for multisensory systems of integrated reading, writing and spelling instruction. Decisions will have to be made in regard to providing group experiences for children on prescription, so that they do not find themselves working in isolation on seatwork activities for much of the day. Peer tutoring and paraprofessional aides have a place in prescriptive programming.

\section{Adaptation of Published Materials}

Usually, only portions of adopted basal readers, arithmetic, social studies, and spelling texts are appropriate for children with skills deficits. Texts must be supplemented by skill-building activities selected from a variety of sources, as well as by teacher-made materials. Because development of materials is often prohibitive in terms of time, many teachers find that they can adapt available materials to meet special needs.

Simple adaptation measures might include reducing the number of arithmetic problems on a page by cutting the page into four parts to be presented separately or making a task more concrete by supplementing a word problem involving addition of sets with objects which can be counted to correspond to the sets. Moderate levels of adaption could include recording word problems on tape and permitting the child to listen to rather than read them or preparing a set of questions for a page of social studies material to be studied before the page is read as an aid to comprehension. More complex adaptations are such measures as the application of readability formulas in order to match the reading level of materials in content areas to the child's instructional reading level or, alternatively, arranging for another child or an aide to put content-area materials such as social studies chapters on tape.

Teachers who are well-acquainted with a variety of materials can usually locate a published lesson which can serve a particular purpose. Just as an automobile mechanic might "cannibalize" several cars to find parts to repair one automobile, so the teacher must take apart published materials to find appropriate parts to repair skills deficits. Of course, access to a well-equipped materials center is ideal for prescriptive teaching, but it cannot substitute for a knowledge of materials and the creativity to find a new way to use a familiar material. Careful selection and adaptation of materials can mean hours of time and considerable effort conserved in prescriptive teaching.

\section{DEVELOP A TIME-LINE FOR THE PROGRAM}

In determining a time-frame in which to implement the instruction, at least three decisions must be made.

Estimate of the Number of Trials Required to Meet Criterion. An impression of how quickly a child might be expected to respond to instruction aids in long-term planning. If five top-priority skills are incorporated in the prescription, the teacher should know from informal testing which of these is likely to be most difficult or require the most work to meet the objective. This estimate controls the decision about frequency of presentation.

Sequence and Frequency of Task Activity. In addition to the estimate of the number of trials required to meet criterion, the priorities for remediation must be considered in determining how often tasks will be presented. Highest priority skills will be presented daily, with lower-priority skills practiced several times a week. The sequence of task activity in any given day might also be controlled by priority, with more critical skills presented early for the best learning conditions.

Time'Block for Each Task. The question of whether to provide massed practice or spaced practice must be considered. For children with limited attention to task, 
two ten-minute sessions a day on a single skill would be preferable to one twenty-minute session. But if a sequence of concepts must be developed for a given task, a single twenty-minute session might be the time block of choice to ensure incremental learning.

\section{IMPLEMENT THE PRESCRIPTION}

All of the decisions made earlier culminate in the trial teaching which puts the prescription into practice. The prescription development is not complete until the methods and materials have been evaluated in interaction with the child. The teacher should plan to implement only one new prescription a day and allow extra time to devote to the target child.

\section{Arrangement of Materials and Instructions}

Materials should be placed so that the student can take them from storage and arrange them for use himself. Materials should be placed across the room from the child's desk so that he returns completed work and picks up the next task throughout the day. This serves the purpose of providing the teacher with a highly visible check on his progress through his work, since she can note his beginning and ending times for each task from any point in the room and she can note the times for computation of rate. The schedule for the day should be written for each child and taped to his desk so that he can refer to it and be independent in moving from task to task. A dittoed sheet which requires only the insertion of page numbers saves time. If the child is to work with an aide, it should be clear who will initiate the sessions. In order to avoid interruptions, the teacher should instruct the child in the operation of tapes, filmstrips, records, or other aids.

\section{Adjustment of Physical Conditions}

To permit access to electrical outlets or to limit distractions, it may be necessary to arrange work centers in the room. A screen that doubles as a bulletin board or a carrel constructed from a large packing box can reduce visual stimuli. Changing the location of a child's desk so that he faces a wall for part of the morning may serve the same purpose. Auditory distractions can usually be reduced by cuing the child in advance about the sounds he will hear while he works. If he knows that the class will be moving about for reading groups, for example, he may not find it necessary to look up when he hears them.

\section{Demonstration of the Initial Lesson for Each Objective}

Although ultimately the child takes responsibility for his own daily program, initially it is wise to involve the teacher closely in the activities of the prescription. If the teacher is to work one-to-one with the child on a daily basis, make this the first activity on the first day of the prescription so that the child gets a set for moving right into a task. If an aide is to work with him, the teacher should still introduce and observe the first lesson to endorse the aide's work and express interest. Even on independent seatwork, the teacher should demonstrate the task and watch the child respond to a few items of each activity so that the lesson gets off to a good start. The teacher's proximity and enthusiasm should set a tone of cooperative work.

\section{EVALUATE THE PRESCRIPTION}

Since the prescription is viewed as a dynamic rather than a static diagnostic-remedial approach, an essential part of the process is the ongoing evaluation system. There are a number of ways to determine the child's progress through the program.

\section{Direct Product and Time Records}

Appropriate for independent seatwork, this type of record allows the teacher to graph each day how much work is completed in a certain time unit. By noting the time when a student picked up a worksheet and the time at which he returned it, the teacher can estimate his rate. This enables her to judge whether a time contingency should be added, such as utilizing a kitchen timer for decreasing intervals and rewarding the child for beating the clock, or whether time should be increased as a means to improve deliberation and accuracy. The child's daily work products plus the teacher's observations of time allow for a good measure by which to adjust the daily program.

\section{Number of Trials per Lesson}

For work done with the aide or the teacher, a graph should be kept showing how many trials of a given task are presented each session. This kind of information sometimes reveals that tasks are not appropriately sequenced or 
that they are not in small enough steps. If a child who has been learning two new spelling words a day with five trials on the average suddenly requires ten trials each day, the teacher is alerted that an adjustment is needed.

\section{Consumer Satisfaction}

Feedback should be solicited from the child to determine how well the prescription is working. An interview between teacher and child at regular intervals, perhaps five minutes at the end of each week, can provide the format for the child's perceptions of the prescription and any adjustments he might request. Again, the child's continuing cooperation is enlisted toward joint goals.

\section{MODIFY THE PRESCRIPTION}

Despite the time and effort devoted to the prescription thus far, it will not succeed unless the teacher is responsive to the interaction of the child with the instructional program. Careful observation of the child's on-task behavior plus the records which are kept daily and the interviews with the child combine to yield the information necessary to make adjustments in the program. Changes might involve the type of material or the method of presentation, the stimulus or response mode, the complexity of the task or the amount of work presented in one session, the time block or the sequence of tasks, the type or schedule of reinforcement. No alteration is made without a rationale, but the flexibility to change in response to a demonstrated need is essential to the diagnostic-prescriptive process.

\section{REFERENCES}

Beery, K. Remedialdiagnosis. San Rafael, California: Dimensions Publishing, 1968.

Betts, E. A. Foundations of reading instruction. New York: American Book Co., 1957.

Fleming, E. S. \& Anttonen, R. G. Do teachers get what they expect? The self-fulfilling prophecy revisited. Childhood Education, 1971, 47, 451-453.

Kibler, R. J., Barker, L. L. \& Miles, D. T. Behavioral objectives and instruction. Boston: Allyn \& Bacon, 1970.

Kress, R. \& Johnson, M. Informal reading inventories. Newark, Del.: International Reading Association, 1965.

Lerner, J. Children with learning disabilities. Boston: Houghton Mifflin, 1971.

Mager, R. F . Preparing instructional objectives. Belmont, Calif.: Fearon Publishers, 1962.

Otto, W. \& McMenemy, R. A. Corrective and remedial teaching. Boston: Houghton Mifflin, 1966.

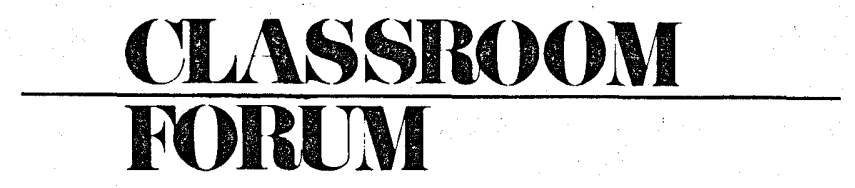

Edited by Alwyn H. Holloway
Georgia State University and
South Dekalb Children's Center

I have taught in a self-contained learning disabilities classroom for the past few years. This year I have been assigned to a resource learning disabilities class. I am finding it difficult to organize and plan for groups that change so often. Can you give me some hints for organization of the resource room as well as some activities that might be used in such a class?

In the past few years there has been a trend toward the establishment of resource rooms for those who have learning disabilities as well as those who have behavior disorders and who are educably mentally retarded. A resource room can serve more students in its caseload and can serve them in small, manageable groups. It can also serve to bridge a gap for those leaving special class placement to join regular classrooms. The resource room helps to keep the mildly impaired child in the regular educational mainstream, which has many advantages.

Just what is a resource class? Weiderholt (1974) defines it as "any special educational instructional setting to which a child comes for a specific period of time on a regularly scheduled basis for remedial instruction." Therefore, the primary responsibility of a resource teacher is usually to serve a regular caseload of children needing special help. However, there are additional consultative responsibilities that will be discussed in a subsequent issue.

The regular caseload usually consists of those with mild to moderate impairments. The total caseload includes 15-20 students, which is a flexible number and depends on the size of the classroom, the materials and equipment available, the severity of the problems, and ages of the students.

Students are usually seen four to five days a week at a regularly scheduled time. The session may vary in length from 30 to 60 minutes, depending on the size and age of groups. Group sizes vary from two to six members in most 
cases, though occasionally a student may be seen individually. Group members are placed according to age and disability. Scheduling the groups is often difficult but, as a general rule, the youngest children are scheduled early in the day. Scheduling has to be closely coordinated with the regular classroom teachers in order to find a suitable time for the student to be away from class. Close cooperation during scheduling may prevent future problems.

Just what types of remedial and instructional programs are utilized in a resource room depend on the students and teachers. Even though the groups consist of those of similar ages and disabilities, the programs must still be individualized. As a general rule, math or reading is emphasized with psycholinguistic remedial activities interspersed throughout. The primary needs of the individual and the group must be ascertained. The resource room is not designed to be solely tutorial, but some supportive teaching may be necessary from time to time. This is a point that should be clarified with regular teachers. If they expect the resource teacher to help the students only with their classwork, then misunderstandings might occur to the detriment of the program.

In planning for the groups, it is helpful to have a sample summary of the group's deficits as well as strengths. A profile sheet utilizing ITPA scores, WISC subtest scores, and academic skills and levels can be computed for the group. Such a sheet helps greatly in programming for the individuals within a group (see sample). Remedial activities planned according to abilities and disabilities can be fun, motivating activities that can be quickly interspersed with academics. It need not be included each day but is helpful at least several times weekly. Programs might include some motor training, language activities (using ideas from Peabody Kits, DUSO Kits, and Bereiter-Englemann series) as well as academic training. For every activity planned, it is important to know why it is being included and what goal it is leading toward.

\begin{tabular}{|l|l|l|l|l|l|}
\hline $\begin{array}{l}\text { (*) Strength } \\
\text { (-) Weakness }\end{array}$ & \multicolumn{3}{|c|}{ PROFILE SHEET } & $\begin{array}{l}\text { Group 2- } \\
\text { Mary, Stan }\end{array}$ \\
\hline $\begin{array}{l}\text { Vis. Rec. } \\
\text { Mary (*) } \\
\text { Stan (*) }\end{array}$ & $\begin{array}{l}\text { Aud. Rec. } \\
\text { Mary (-) } \\
\text { Stan (*) }\end{array}$ & Vis. Clos. & Frostig & $\begin{array}{l}\text { Reading } \\
\text { Comp. }\end{array}$ & \\
\hline $\begin{array}{l}\text { Vis. Ass. } \\
\text { Mary (*) } \\
\text { Stan (-) }\end{array}$ & $\begin{array}{l}\text { Aud. Ass. } \\
\text { Mary (-) } \\
\text { Stan (-) }\end{array}$ & Sound Bl. & Math & $\begin{array}{l}\text { Reading- } \\
\text { Decoding }\end{array}$ & \\
\hline $\begin{array}{l}\text { Vis. Mem. } \\
\text { Mary (*) } \\
\text { Stan (-) }\end{array}$ & $\begin{array}{l}\text { Aud.Mem. } \\
\text { Mary (-) } \\
\text { Stan (-) }\end{array}$ & Aud. Clos. Spelling & R.P.V.T. & \\
\hline
\end{tabular}

Because of the small size of the group, it is possible to use varied techniques. For example, the tape recorder can be used in many ways. A story can be recorded and played while the students lie on the carpeted floor with the lights out. Such a listening activity can be followed by comprehension questions presented in various ways. Students can also follow along in a book while the story is played on the recorder. Learning games can be fun and very reinforcing, provided the purpose of the game is understood and is used in that manner. One session per week might have a learning game scheduled-for example, buzzer boards, spelling games, etc. Role playing can also be used successfully in small groups.

There are several principles that if utilized in a resource setting will promote a more organized, successful program. 1. Make good use of your time. Be ready to go when the students arrive, so that valuable time is not spent gathering and preparing materials while the students are in the room. Before the day starts, all materials and plans should be organized according to groupings. Folders and boxes containing materials to be used in each group help to have equipment readily available for the groups.

2. Make learning fun, but purposeful. Each activity should have a specific objective in line with individual and group goals.

3. Principles of behavior modification can help make the learning more successful. Reinforcement can be given for various behaviors, such as arriving on time, working well in resource room, and other positive behaviors within the group situation. If the student is having problems within his regular class, a checkmark system might be worked out to reinforce for positive behaviors in the regular class. Such a system could also be utilized for some students not in the resource program. "Goodies" from the resource room or special time in the resource room might be bought with checkmarks obtained in the class. This, too, has to be closely coordinated with the regular classroom teacher.

4. Keep abreast of the student's overall school program. Close contact and communication with other teachers is vital.

5. Peer teaching and tutors often prove very beneficial. The resource teacher might be able to coordinate these activities.

Weiderholt, J. L. Planning resource rooms for the mildly handicapped. Focus on Exceptional Children, 1974, 5, 1-10. 


\section{INDEX VOLUME 6}

\section{AUTHOR INDEX}

Beery, Keith E. (November 1974)

Boekel, Norma (April 1974)

Brown, Lou (April 1974)

Carroll, Anne W. (September 1974)

Chaffin, Jerry D. (October 1974)

Hillman, Jr., William A. (May 1974)

Holloway, Alwyn H. (September-February)

Larsen, Stephen C. (January 1975)

Moran, Mary Ross (February 1975)

Neal, Larry L. (May 1974)

Nesbitt, John A. (May 1974)

Reid, Barbara A. (December 1974)

Reid, William R. (December 1974)

York, Robert (April 1974)

Weikart, David P. (March 1974)

\section{CHRONOLOGICAL INDEX OF TITLES}

Curriculum for early childhood special education (March 1974)

Developing programs for severely handicapped students: Teacher training and classroom instruction (April 1974)

Recreation for exceptional children and youth (May 1974)

The classroom as an ecosystem (September 1974)

Will the real "mainstreaming" program please stand up! (or ... should Dunn have done it?) (October 1974)

Mainstreaming: A problem and an opportunity for general education (November 1974)

Role expectations of paraprofessional staff in special education (December 1974)

The influence of teacher expectations on the school performance of handicapped children (January 1975)

Nine steps to the diagnostic prescriptive process in the classroom (February 1975)

Classroom forum (Monthly) 